\title{
Review on Lagrangian Particle Tracking Modeling for Floating Objects around the Korean Peninsula
}

\author{
Young-Gyu Park ${ }^{*} \cdot$ Seongbong Seo ${ }^{* *}$
}

\begin{abstract}
Marine debris is becoming an increasingly serious problem. Using a Lagrangian particle model one can calculate the trajectories of various floating objects including marine debris. We reviewed Lagrangian particle tracking of floating objects in the seas around Korea from three recent studies. The first one was on the fate of marine debris from lands through the rivers discharging into the seas around the Korean Peninsula. The main path of the debris depended on their geographical locations. The debris from the rivers on the east coast of China moved southward along the Chinese coast, to the Korea Strait, or to the North Pacific Ocean via the Kuroshio Current (KC). That from the rivers located on the west coast of the Korean Peninsula moved southward to reach the $\mathrm{KC}$, and then to the North Pacific Ocean. The main pathway of the debris from the Nakdong Rivers was toward the East Sea (ES). The particles released from the Tumen River were limited to the ES. In the second example, the pathways of the debris released through the Tumen River located between the North Korea and Russia during the flooding induced by the typhoon Lionrock in August 2016 were investigated. The debris was transported southward along the east coast of the Korean Peninsula by the southward North Korea Cold Current while affected by the wind. Three potential hotspots of debris accumulation along the coast were also found. In the third example, the most probable route of a wave buoy found at Cape Mendocino, California, USA was deduced. The buoy moved from Jeju Island toward Taiwan, and then to the North Pacific via the KC. These model results would help us to establish efficient cleaning and management plans of marine debris by showing us the main accumulation sites, pathways and source areas.
\end{abstract}

Key words : marine debris, ocean current, windage, trajectory

* Principal Research Scientist, Ocean Circulation Research Center, Korea Institute of Ocean Science and Technology, 385 Haeyang-ro, Yeongdo-gu, Busan 49111, Korea, ypark@kiost.ac.kr

** Assistant Manager, Future Business Development Department, Korea Marine Environment, Management Corporation, 28 Songpa-daero 28-gil, Songpa-gu, Seoul 05718, Korea, sbseo@koem.or.kr 


\section{Introduction}

In the seas around the Korean Peninsula, there are diverse floating materials. Some of them are natural ones such as planktons, algae and larvae, while some are anthropogenic one such plastic wastes, leaked oils, and objects from wrecked vessels. They drift due to ocean currents and winds. Since the average currents and winds of the area are known, it is possible to predict how these floats would move in general. However, in order to respond to an oil pollution accident, rescue a ship or crew in distress, search for a lost object, or identify where marine debris would accumulate or move, it is necessary to evaluate or predict the trajectories of floating objects accurately.

The most common and widely utilized way of calculating the trajectories of various floating objects is Lagrangian particle modeling using ocean currents and winds. Here, we review tracking of floating objects in the seas around Korea using Lagrangian particle modeling based on three recent studies. The first one is on the fate of marine debris from lands conducted by Seo and Park (2020). It is known that about $80 \%$ of marine plastic debris found in the oceans is transported from the land through rivers (Cole et al., 2011; GESAMP, 2016; Li et al., 2016). From this example, we show the destinations of particles from major rivers around the Korean Peninsula. In the second example, which is based on Seo et al. (2020), the origin of the garbages found near Gangneung in Korea, August 2016 was traced. Although we were able to qualitatively estimate the origin from the labels on the garbage, we traced the route quantitatively, and showed how the ocean current and wind shaped the trajectories of the debris. Other areas where the garbage might have been accumulated were also found. The third example, which is Seo and Park (2021), is estimating the route of the wave buoy found on the west coast of the United States. It was a wave buoy managed by the Korea Meteorological Administration near the Jeju Island, and lost on July 31, 2014. From the information on the initial and end points, the most probable route was inferred using a Lagrangian particle tracking model.

In the next section, the Lagrangian particle model was first described, and the above three cases were explained in detail. In the end, other areas where the Lagrangian particle tracking method is applied as well as implications to policies for marine debris management are mentioned briefly.

\section{Lagrangian Particle Tracking Model}

Floating objects are transported by ocean current, and if they are exposed to air by the wind. A Lagrangian particle tracking model calculates the trajectories of floating particles as explained in Seo and Park (2020) as follows: 


$$
\vec{x}_{t+\Delta t}=\vec{x}_{t}+\int_{t}^{t+\Delta t}\left\{\vec{u}_{c}\left(\vec{x}_{t}, \tau\right)+W_{f} \times \vec{w}_{10 m}\left(\vec{x}_{t}, \tau\right)\right\} d \tau+R \sqrt{2 K_{h} \Delta t} .
$$

Here, $\vec{x}_{t}$ is the position of the particle at time $t$, and $\Delta t$ is the time interval. The input data of the model are ocean current $\vec{u}_{c}$, and wind at 10 meters above sea level $\vec{w}_{10 m}$. The wind drift $W_{f} \times \vec{w}_{10 m}$, where $W_{f}$ is the windage coefficient, commonly referred to as the wind drift factor or the wind effect, which is determined by the degree of air exposure (air/water). For completely submerged objects such as small plastic fragments, the windage is $0 \%$. For highly exposed objects such as empty capped plastic bottles and fishing buoys, this increases to $4 \%$ to 5\% (Lebreton et al., 2018; Maximenko et al., 2015; Neuman et al., 2014; Yoon et al., 2010). A random walk component $\left(R \sqrt{2 K_{h} \Delta t}\right)$ is used to simulate unresolved processes and sub-grid scale turbulent motion (North et al., 2006). Here, random number $\mathrm{R}$ is between -1 and 1 , and $K_{h}$, a horizontal diffusion coefficient, is calculated using the Smagorinsky (1963) mixing scheme (Choi et al., 2018; Iwasaki et al., 2017).

One could build own input data using ocean and atmospheric models. On the other hand, one could use regional or global ocean circulation model and atmospheric model outputs provided by several institutes through the Internet. Since running ocean and atmospheric models requires much effort and resources, the latter approached that is utilizing available ocean current and wind data is more commonly used. Of course, it is possible to calculate the particle trajectories within an ocean circulation model. This approach is not efficient because even small changes to the condition require the entire computation to be re-performed. The accuracy of a Lagrangian particle model is mainly determined by the input data, the ocean current and wind. Thus, the quality or validity of the input data as well as the results of a Lagrangian particle model should be validated by comparing with available observation data.

We utilized publically available ocean and atmospheric model outputs as the input data of our Lagrangian modeling. Among several available data we used the $1 / 12^{\circ}$ global field from the HYbrid Coordinate Ocean Model (HYCOM, expt90-91.X, GOFS 3.0, https://www.hycom.org) for the ocean currents, $\vec{u}_{c}$. Into the HYCOM diverse observation data such as satellite altimeter, sea surface temperature, and profiles from Argo floats are assimilated. The HYCOM reproduces the major currents around the Korean Peninsula shown in Figure 1 (Hong et al., 2018; Hu et al., 2017; Li et al., 2016; Seo et al., 2013). For the $10 \mathrm{~m}$ wind, $\vec{w}_{10 m}$, we used either the European Centre for Medium-Range Weather Forecasting (ECMWF) interim reanalysis data (Dee et al., 2011) or the Unified Model $12 \mathrm{~km}$ Regional forecast data (UM) by the Korea Meteorological Administration. The former reproduces the northwest winter monsoon due to the Siberian high-pressure system on the East Asian continent (Chu et al., 2001; Zhang et al., 1997), and southerly summer monsoon (Qian and Lee, 2000) of the northwest Pacific well. The latter also reproduces the wind pattern around the Korean Peninsula well. 
Figure 1. Schematic flow patterns around the Korean Peninsula from The Korea Hydrographic and Oceanographic Agency (KHOA) and the location of the majors considered.

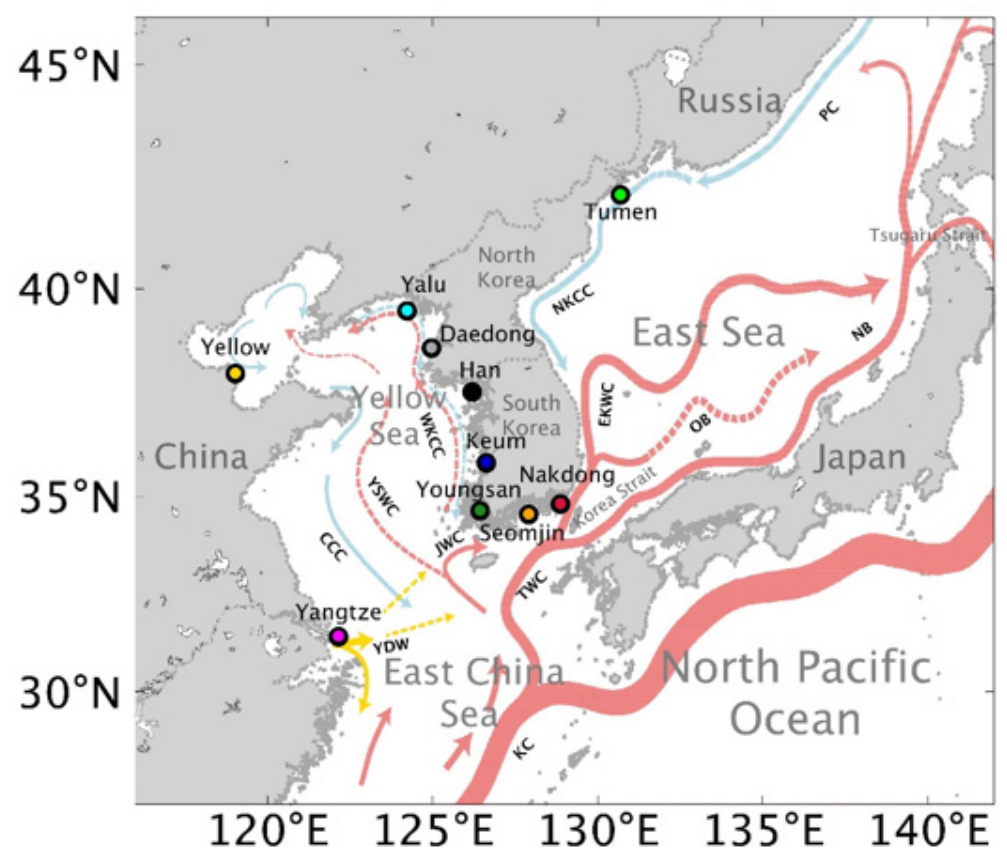

Red and blue lines indicate warm and cold currents, respectively. Yellow line indicates Yangtze Diluted Water (YDW). Solid lines are currents that are permanent throughout the year, and dashed lines are those that change seasonally. TWC stands for the Tsushima Warm Current, EKWC, the East Korea Warm Current, NB the Nearshore branch of TWC, OB the Offshore branch of TWC, NKCC the North Korea Cold Current, PC the Primorye Cold Current, YSWC the Yellow Sea Warm Current, JWC the Jeju Warm Current, WKCC the West Korea Coastal Current, CCC the Chinese Coastal Current, and KC the Kuroshio Current. This figure is adopted from Seo and Park (2020).

\section{Results}

In this section, we describe how such a Lagrangian particle model is applied to the tracking of floating objects in the seas around the Korean Peninsula based on three recent studies. The main focuses are given to the ways the ocean current and wind shaping the trajectories.

\subsection{Destination of Floating Debris from Major Rivers around the Korean Peninsula}

This part is based on Seo and Park (2020). The seas around the Korean 
Peninsula are more contaminated with plastic than in other areas (Isobe et al., 2015; Shim et al., 2018). To cope with this high plastic pollution, we need to know the origin of the pollutant. It is known that globally approximately $80 \%$ of marine plastic waste is originated from land ( $\mathrm{Li}$ et al., 2016), mainly through rivers (Cole et al., 2011; GESAMP, 2016). There are two main factors determining the amount of plastic waste from a river. The first one is the population over the catchment area of the river. Humans consume plastic and produce waste. Another factor is management. If plastic waste is properly collected and disposed or recycled, it does not enter the environment. To quantify the waste management systems, Jambeck et al. (2015) introduced the Mismanaged Plastic Waste (MPW) ratio. The management system differs in each country, and so does the MPW ratio. The MPW ratio of the Republic of Korea is $0.002 \mathrm{~kg} /$ person/day, and that for China is 0.092 $\mathrm{kg} /$ person/day. By multiplying the MPW ratio and population, we can estimated the total amount of plastic waste, or MPW production.

The trajectories of marine debris from the ten rivers discharging into the seas around the Korean Peninsula (Figure 1) were traced using Lagrangian particle tracking modeling. Among the ten rivers, the Yangtze and the Yellow Rivers have the highest MPW production. From each river particles were released every day from January 1, 2010 to December 31, 2015. Each particle were traced for one year from the release data. To simulate different types of debris, each calculation was repeated with 6 different windage values, increasing from $0 \%$ to $5 \%$ with an $1 \%$ increment. The trajectories of the particles are complex and we used the probability function introduced by Rypina et al. (2014) that shows the main pathway and mean travel time of the particles from the initial points. In Figures 2 and 3, the results from five selected rivers are shown.

As shown in Figure 2, at the absence of the wind effect, the particles from the Yangtze River dispersed through three main pathways. The first one was toward the East China Sea (ECS) and then to the Korea Strait (KS) to reach the southern part of the East Sea (ES). The second one was to the ECS and then to the North Pacific Ocean via the Kuroshio Current (KC). These two flow patterns are consistent with those reported by Isobe et al. (2009) and Kako et al. (2010). The third one was southward movement along the Chinese coast. As the windage increases, the eastward transport was reduced and the flux to the Yellow Sea (YS) intensified.

When windage was $0 \%$, the particles from the Yalu and Han Rivers that are located on the west coast of the Korean Peninsula moved southward through the YS to reach the ECS. They then joined the KC to move to the North Pacific Ocean. As the windage was increased, the amount of the particles moving southward along the Chinese coast was increased, while that moving toward the North Pacific Ocean was reduced. The main pathway of the particles released from the Nakdong Rivers was toward the ES. Under higher windage values, the amount of the particles reaching the southern part of the ES was reduced. The amount of particles reaching the ECS, instead, was increased as in Yoon et al. (2010). The particles released from 
Figure 2. Probability of particles from the Yangtze, Yalu, Han, Nakdong, and Tumen Rivers under different windage values.
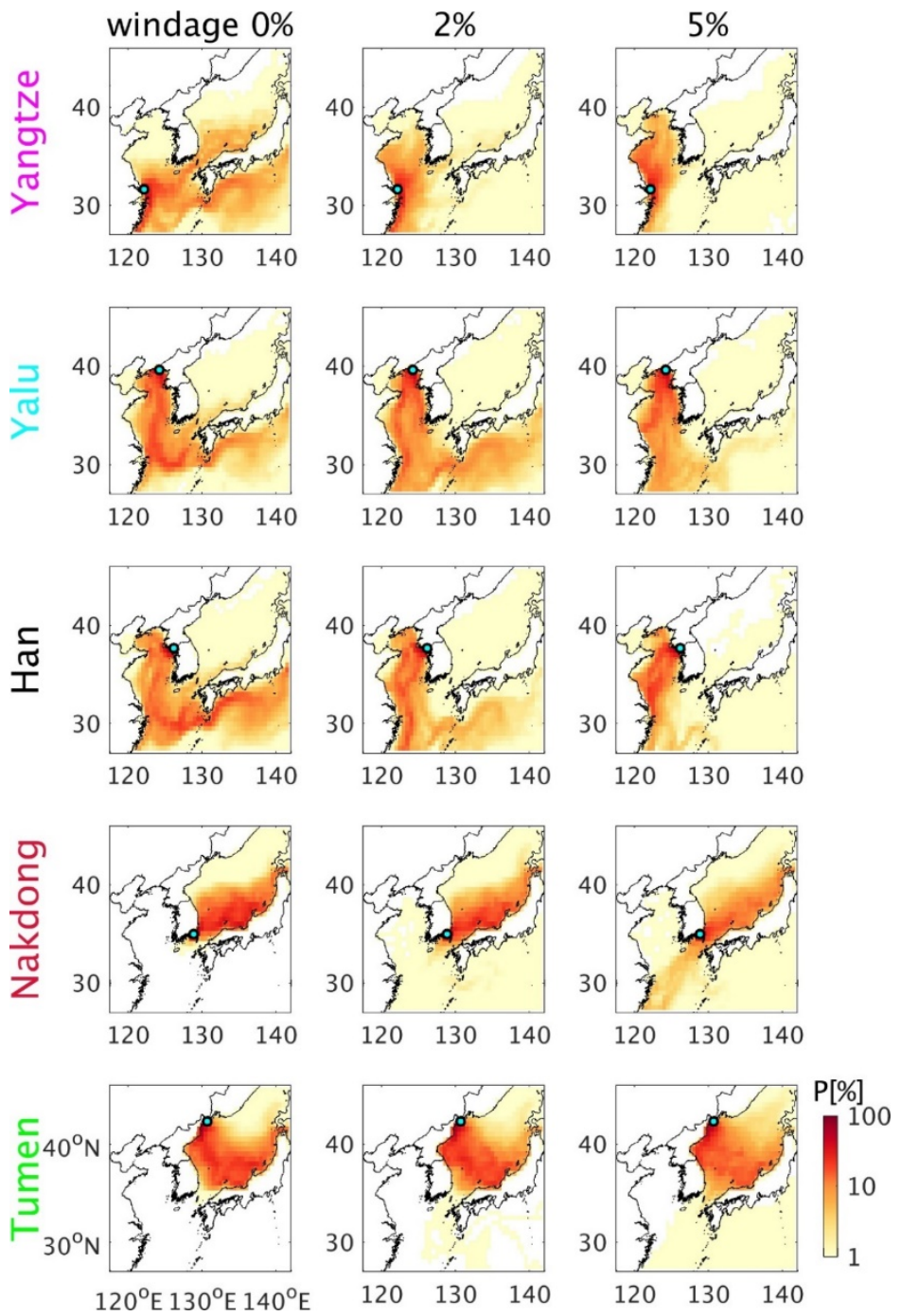

Adapted from Seo and Park (2020) with CC-BY-NC-ND.

the Tumen River was limited to the ES. Under higher windage values, a small amount of particles moved to the KS and then to the ECS. The particles from the Nakdong and Tumen Rivers would disperse more as the windage increases as in Neumann et al. (2014). On the other hand the particles from the Yangtze, Yalu, and Han Rivers dispersed less under higher windage because of the wind induced transport toward the Chines coast. 
Figure 3. The same as Figure 2 except for travel time.
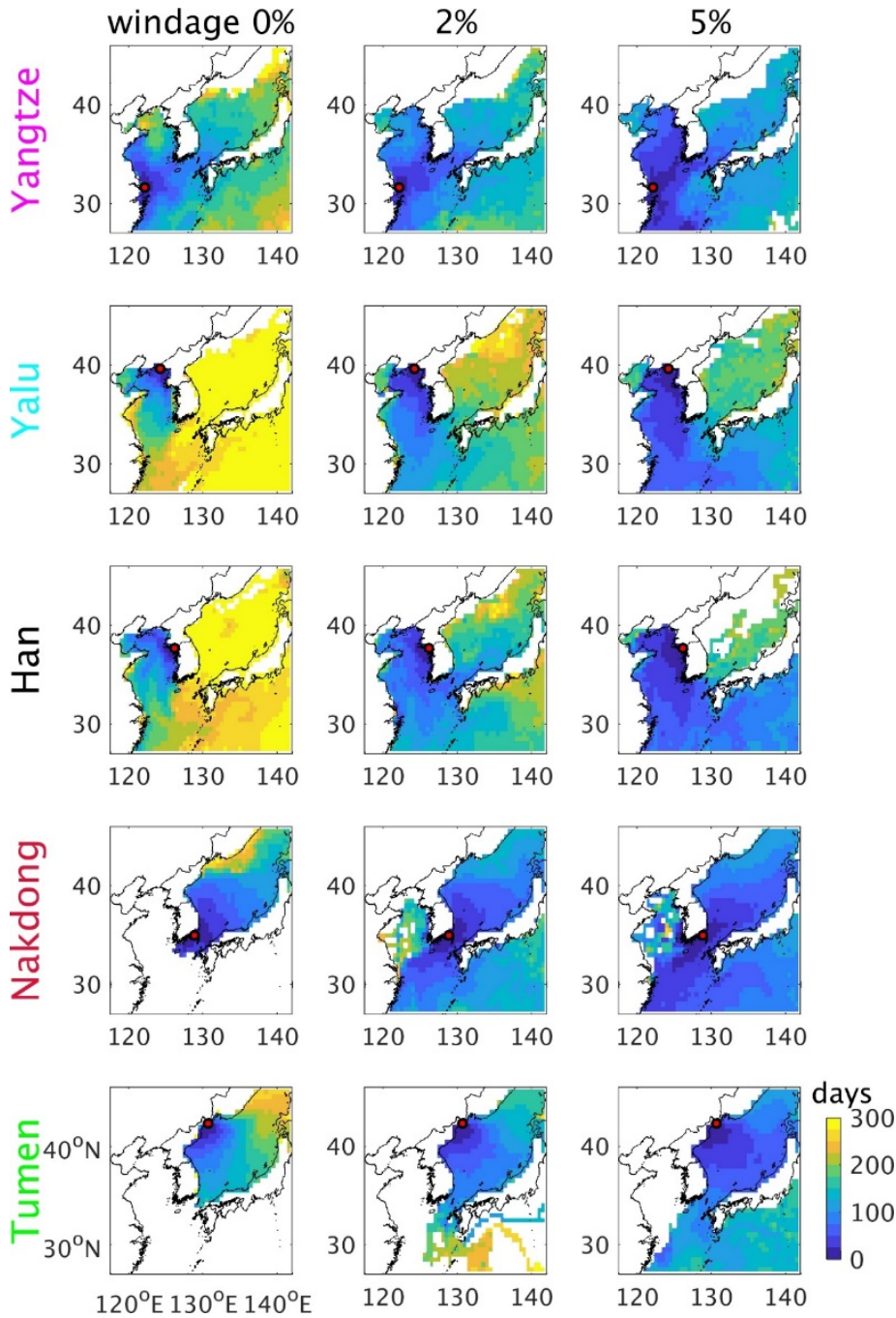

Adapted from Seo and Park (2020) with CC-BY-NC-ND.

The travel time of a particle, of course, increased as the particle moved farther away from the starting points (Figure 3). Along the main pathway, where the probability is high, the travel time is smaller. It took about 100 days for the particles released from the Yangtze River to arrive at the Korean Peninsula. Under about $2 \%$ windage, the travel time to the Korean Peninsula was reduced by half to approximately 50 days. The particles from the Yalu and Han Rivers needed about 100 to 200 days to the Yangtze River mouth, and 200 to 300 days to the North 
Pacific Ocean. Under higher windage values, it took less to the Yangtze River mouth and the North Pacific Ocean. The particles from the Nakdong Rivers spent approximately 150 days to arrive at the Tsugaru Strait. Under 5\% windage, the particles were accelerated, and it took about 100 days to the strait. A small number of particles spent about 50 days to reach the ECS. Under $0 \%$ windage, the particles from the Tumen River arrived at the northern coast of Japan in about 150 days. When the windage was $3 \%$ or greater, they reached there within approximately 100 days. The wind accelerated the drift of the particles to reduce the travel time in all cases considered here.

\subsection{Tracking of Flood Induced Debris}

This part is based on Seo et al. (2020). On August 31, 2016, the heavy rain due to the typhoon Lionrock induced flooding along the Tumen River (Figure 1). On September 14, 2016, logs and household garbage were found near Gangneung, South Korea, which is located at about $800 \mathrm{~km}$ south of the river along the coastline. From the label on plastic bottles, it was rather clear that they were originated from the river. Since the ones landed on Gangneung was a part of the materials released from the river, to respond to potential hazards due to flooding one need to trace other materials that were still drifting in the ocean or landed on other areas. Large floating objects such as logs could be dangerous to marine traffic (Hall, 2000).

The trajectories of the floating objects from the river during the flooding were investigated using Lagrangian tracking modeling. Divers objects including plastic, log and household garbage were found on Gangneung. To account for the diverse buoyancy of the objects, the windage, $W_{f}$, was varied from $0 \%$ to $4 \%$ by $0.5 \%$ increment (Duhec et al., 2015) while conducting nine experiments. The total amount of the objects discharged during the flooding is unknown, but it should be proportional to the river discharge rate. Therefore, in the model the number of the particles discharged from August 30 to September 6 were proportional to the river discharge rate.

In Figure 4, the trajectories of the particles under $0 \%, 2 \%$, and $4 \%$ windage are shown. Regardless of the windage, the particles were transported southward along the coast by the southward North Korea Cold Current. The wind contributes in two ways. First, the wind component parallel to the North Korea Cold Current (NKCC) accelerated the southward transport of the particles. This effect was cumulative, and the difference between $0 \%, 2 \%$, and $4 \%$ windage cases became greater downstream. At Gangneung debris was found on September 14. Particles with higher windage value did arrive there on that date, but the ones with $0 \%$ windage did not. The second contribution of the wind was offshore dispersion due to occasional offshore winds. This offshore dispersion effect also intensifies with windage, but it was not strong enough to modify the main trajectories of the particles. 
Figure 4. Modelled particle trajectory under $0 \%, 2 \%$, and $4 \%$ windage values, respectively, on September (a) 6 (b) 14 and (c) 20. The soild dot represents the

Tumen River where the particles were released.

(a) September 06

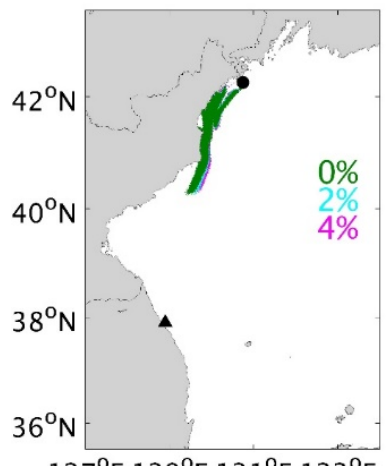

(b) September 14

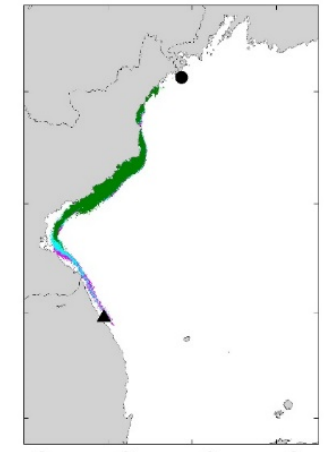

(c) September 20

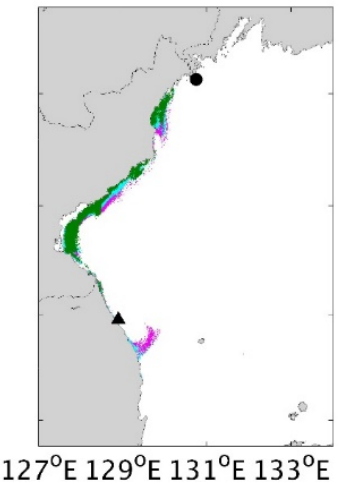

Adapted from Seo et al. (2020) with CC-BY.

Since the diverse objects were found at Gangneung, a composite of the nine cases was constructed and beaching behavior of the particles was analyzed. As in Seo and Park (2020), particles mostly beached near the river mouth. Away from the river mouth, three 'hot spots' of debris accumulation were found as displayed with green, blue and black boxes in Figure 5. The numbers of accumulated particle in the gird of the greatest amount in each hot spot, from north to south, was 105, 59,85 times of that of the grid for Gangneung, respectively. To find the causes of the hotspots, the structures of the current and wind were analyzed. The two northern Hotspots A and B were due to onshore currents toward the cape-shaped coast. On the other hands, the wind was predominantly in the alongshore direction. Under high wind effect, particles would move southward before reaching the coast, and fewer particles were beached. Over the southernmost Hotspot $\mathrm{C}$, the winds were in the onshore direction. As the windage became stronger from zero to $2.5 \%$, the numbers of accumulated particles would increase. As the windage became larger than $2.5 \%$, due the enhanced offshore dispersion in the upstream, the amount of the particles reaching this area was reduced, and so did the beached ones. In short, the southernmost hot spot was due to the prevailing onshore wind as in Critchell et al. (2015) and Moy et al. (2018), while the two northern hotspots were due to the onshore current and the shape of the coastline.

\subsection{Tracking a Coastal Wave Buoy Lost from the Southern Coast of Jeju Island}

This part is based on Seo and Park (2021). In April 2020 a buoy was found 
Figure 5. Distribution pattern of beached particle in the composite of $0 \%, 2 \%$, and $4 \%$ windage cases. All particles beached until October 20, which was 50 days after the initiation of the experiment, were counted. The 3 colored boxes (a), (b), and (c) indicate hotspots of beaching, and the gray and violet vectors in each box indicate the mean ocean current and wind during September 2016.

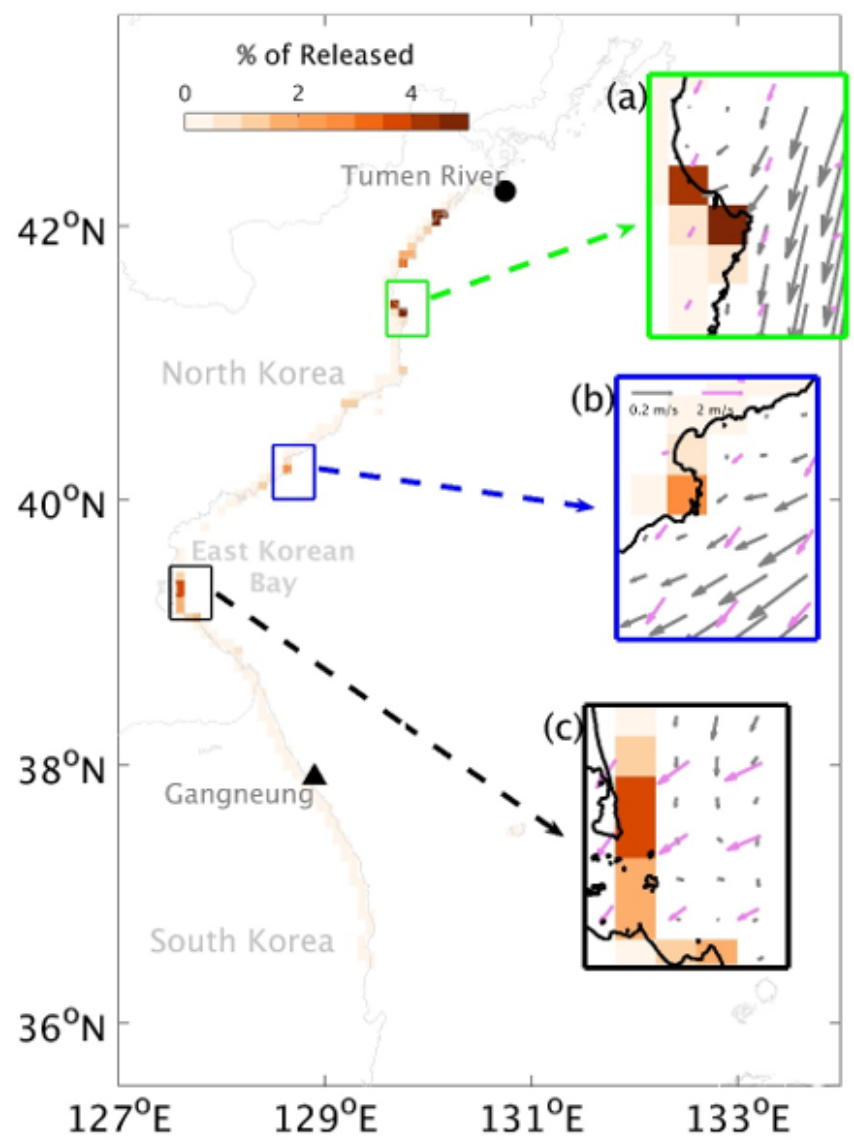

Adapted from Seo et al. (2020) with CC-BY.

Cape Mendocino, California, USA. It was a coastal wave buoy managed by the Korea Meteorological Administration in the southern coastal area of Jeju Island. It was believed to be lost on July 31, 2014, and then drifted for approximately 2070 days to Cape Mendocino. Since the buoy was not equipped with a tracking device, the path of the buoy could not be determined. Instead, a Lagrangian particle tracking model was used to deduce the most probable path of the buoy. The windage of the buoy was about $2 \%$ to $4 \%$, since the exposure rate was about $40 \%-$ $60 \%$. Thus, three experiments were performed with three different windage values, 
which were $0 \%, 2 \%$, and $4 \%$. Along a strip located at the southern coast of Jeju Island, 500 particles were released daily from July 31 to August 8, 2014.

The trajectories of the particles presented in Figure 6 show that the wind was as important factor as the ocean currents. At the absence of wind ( $0 \%$ windage), the particles moved to the ES and then to the North Pacific Ocean. When the windage was increased to $2 \%$, the particles moved to the ECS and then to the North Pacific. Both in $0 \%$ and $2 \%$ cases, the particles entered the northwestern were

Figure 6. Mean probability distribution of particles from Jeju Island under (a) $0 \%$, (b) $2 \%$, and (c) $4 \%$ windage values. Blue contours denote the mean travel time over the area where probabilities were greater than $1 \%$. The grid cells used to calculate the probability are also shown. The green dot represents release point, the Jeju Island, and the purple one Cape Mendocino where the buoy was found.

(a) $0 \%$ windage

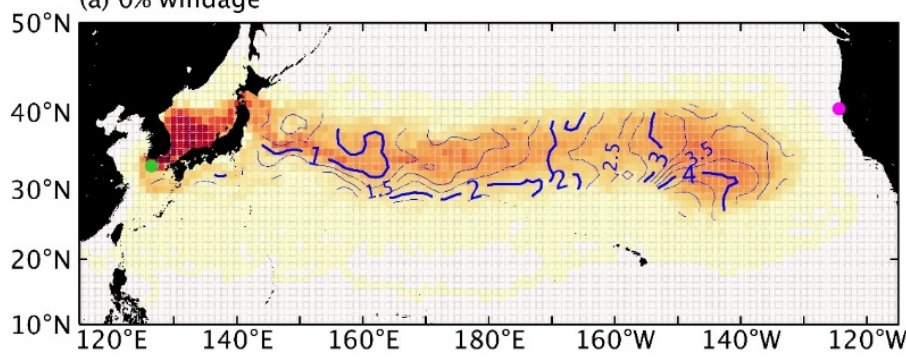

(b) $2 \%$ windage

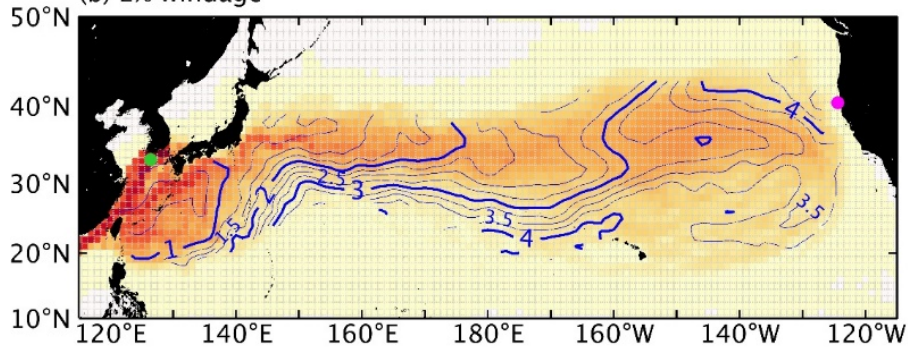

(c) $4 \%$ windage

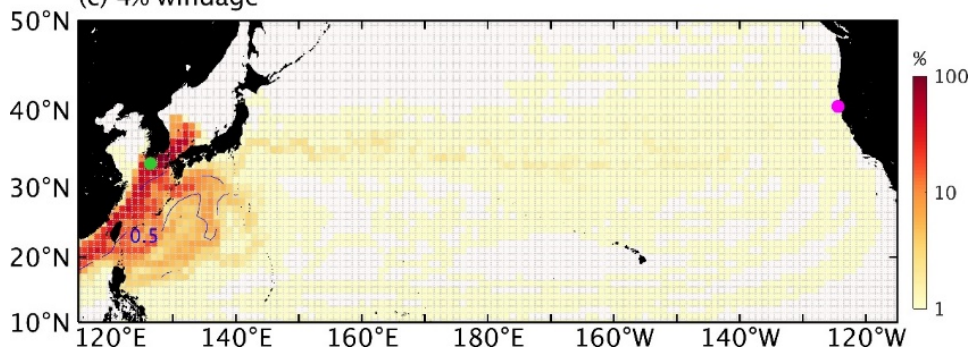

Adapted from Seo and Park (2021) with CC-BY. 
mainly accumulated in the Great Pacific Debris Patch (GPGP). Under 4\% windage, the main portion the particles were transported to the South China Sea (SCS) through the ECS or beached due to northeasterly winds. A small numbers of the particles moved to the North Pacific beyond $150^{\circ} \mathrm{E}$. If particles are released during a different season, the particles would take different trajectories because of the strong seasonality of the wind around Korea.

Without the wind effect, the particles entered the GPGP were not able to leave there. With $2 \%$ windage, a small number of particles were able to escape the GPGP, and started to arrive at Cape Mendocino 2 years and 7 months after the release (Figure 7). The buoy spent about 5 years and 8 months to move from Jeju Island to Cape Mendocino. We found a particle that spent about the same time, and deduced the most probable trajectory of the buoy using the particle. Due to the northeasterly wind, the buoy first traveled toward Taiwan. Upon reaching east of Taiwan, it was carried by the KC, Kuroshio Extension, and North Pacific Current to the subtropical convergence zone in which the GPGP is located. The particle spent about two years to arrive there. It then anticyclonically circulated the convergence zone once in another two years approximately. Due to the westerly wind the particle was pushed from the convergence zone to Cape Mendocino. When windage was $4 \%$, only one particle arrived there. The travel time was approximately 1 year and 9 months, and was much shorter than that of the buoy.

Figure 7. The trajectories of the particles reaching Cape Mendocino under $2 \%$ windage. Among them the most probable trajectory of the buoy (the path of a particle that took 5 years and 8 months to reach the destination) is highlighted and colored according to the chronology along the trajectory.

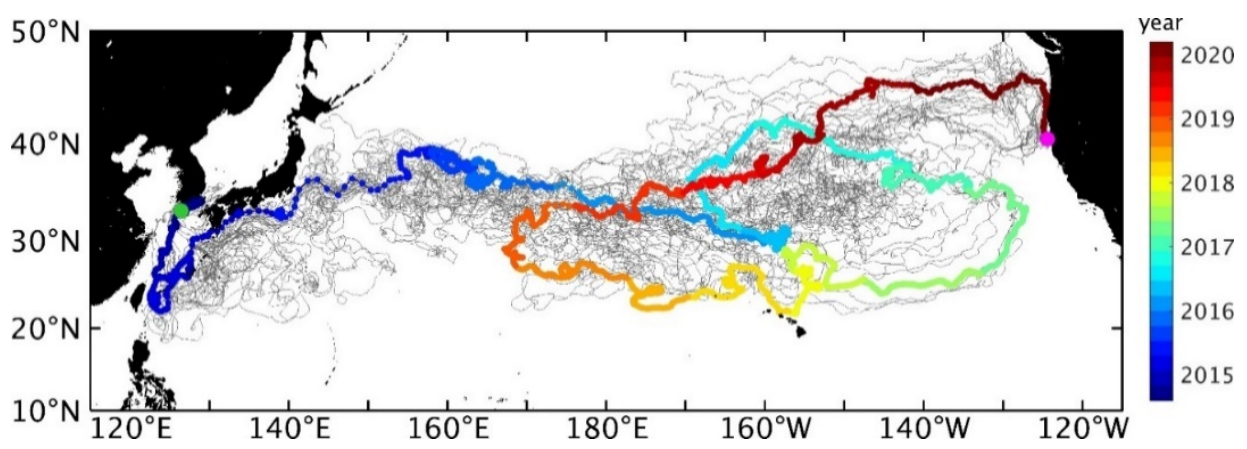

Adapted from Seo and Park (2021) with CC-BY.

\section{Summary and Conclusion}

In the seas around the Korean Peninsula, there are diverse floating 
materials. Floating objects are transported by ocean current, and if they are exposed to air by the wind. With a Lagrangian particle model, one can calculated the trajectories of various floating objects relatively quickly using ocean currents and winds, which become readily available recently. The accuracy of a Lagrangian particle model is largely determined by the input data, the ocean current and wind. Thus, the quality or validity of the input data should be assessed by comparing with available observational data. The results also must be validated using relevant observational data, which in some case are rare, before conducting in depth analysis.

Here, we reviewed Lagrangian particle tracking modeling of floating objects in the seas around Korea based on three recent case studies. The first case, which is from Seo and Park (2020), was on the fate of marine debris from lands through the rivers discharging into the seas around the Korean Peninsula. It was found that the main path of the debris depended on their geographical locations. At the absence of the wind effect, particles from the rivers on the east coast of China moved southward along the Chinese coast, to the KS, or to the North Pacific Ocean via the $\mathrm{KC}$. The particles from the rivers located on the west coast of the Korean Peninsula moved southward to reach the $\mathrm{KC}$ and then to the North Pacific Ocean. As the wind effect increased, the amount of the particles moving southward along the Chinese coast was increased, while that moving toward the North Pacific Ocean was reduced. The main pathway of the particles released from the Nakdong River that is located on the southern coast of the peninsula was toward the ES. The particles released from the Tumen River that is located between North Korea and Russia and discharging into the ES were limited to the ES. The particles from the Nakdong and Tumen Rivers would disperse more as the windage increase as in Neumann et al. (2014). On the other hand, the particles from the Yangtze, Yalu, and Han Rivers dispersed less under higher windage because of the wind induced transport toward the Chines coast. The wind accelerated the drift of the particles to reduce the travel time in all cases considered here.

In the second case, which is from Seo et al. (2020), the pathways of the debris released from the Tumen River during the flooding induced by the typhoon Lionrock in August 2016 were investigated. We showed how the ocean current and wind shaped the trajectories of the debris. Regardless of the wind effect, the particles were transported southward along the east coast of the Korean Peninsula by the southward North Korea Cold Current. The wind accelerated the southward drift and enhanced offshore dispersion of the particles. The latter effect of the wind was not strong enough to modify the main trajectories of the particles. Three possible hotspots of debris accumulation were found. It was estimated that approximately 50 to 100 times more debris was beached in these hotspots than in Gangneung. The southernmost hotspot was due to the prevailing onshore wind as in Critchell et al. (2015) and Moy et al. (2018), while the two northern hotspots were due to the onshore current and the shape of the coastline. Unfortunately, due to the lack of observational data, the presence of the hotspots could not be 
substantiated.

In the third example, which is from Seo and Park (2021), the most probable route of a wave buoy that was found at Cape Mendocino, California, USA after being lost in the waters near the Jeju Island was estimated. The exposure rate of the buoy was about $40 \%-60 \%$, and the windage should be about $2 \%$ to $4 \%$. Under $2 \%$ windage, there was a particle that spent about 5 years and 8 months to move from Jeju Island to Cape Mendocino as the buoy. From the trajectory of the particle, we deduced the most probable trajectory of the buoy. After begin lost, the buoy first traveled toward Taiwan under the influence of the northeasterly wind. Upon arriving at east of Taiwan, it was carried by the $\mathrm{KC}$, Kuroshio Extension, and North Pacific Current to the subtropical convergence zone in which the GPGP is located. It took about two years for the particle to reach there. It then anticyclonically circulated the convergence zone once in another two years approximately. Due to the westerly wind, the particle was pushed from the convergence zone to Cape Mendocino.

In the cases reviewed here, the HYCOM data were used for the ocean current, because they reproduce the major currents around the Korean Peninsula properly (Hong et al., 2018; Hu et al., 2017; Li et al., 2016; Seo et al., 2013). For the $10 \mathrm{~m}$ wind, we used either the ECMWF interim reanalysis data (Dee et al., 2011) or the UM data by the Korea Meteorological Administration. Both of them are known to reproduce the wind pattern around the Korean Peninsula well.

Marine debris is becoming an increasingly serious problem, and many reduction measures are being established. If we know the main beaching areas or main routes of marine debris, which we can assess with Largrangian modeling, we could establish an efficient plan or strategy for its removal. It is much easier to remove marine debris in rivers than in the oceans. Therefore, Largrangian modeling will help us to establish effective reduction measures by showing the source areas of marine debris.

Although we have only reviewed three cases related to floating objects around Korea, particle tracking modeling can be applied to many different areas related to any floating objects as reviewed in van Sebille et al. (2018). As the number of floating objects increases, the demand and applications for Lagrangain particle tracking modeling will continue to grow. We have applied this particle tracking modeling to predict the movement of green algae (Son et al., 2015), which is blooming in the ECS and moving toward Korea. Currently, we are developing a prediction system for brown algae (Sargassum) patch transport. Such a system would help the stake holders establishing an efficient and precise removal plan at least a few days in advance.

\section{Acknowledgments}

This work was funded through the projects entitled "Influences of the 
Northwest Pacific circulation and climate variability on the Korean water changes and material cycle I-The role of Jeju warm current and its variability" from Korea Institute of Ocean Science and Technology.

\section{References}

Choi, J. G., Jo, Y. H., Moon, I. J., Park, J., Kim, D. W., and Lippmann, T. C. (2018). Physical Forces Determine the Annual Bloom Intensity of the Giant Jellyfish Nemopilema Nomurai Off the Coast of Korea. Regional Studies in Marine Science 24:55-65.

Chu, P. C., Lan, J., and Fan, C. (2001). Japan Sea Thermohaline Structure and Circulation. Part I: Climatology. Journal of Physical Oceanography 31(1):244-271.

Cole, M., Lindeque, P., Halsband, C., and Galloway, T. S. (2011). Microplastics as Contaminants in the Marine Environment: A Review. Marine Pollution Bulletin 62(12):2588-2597.

Critchell, K., Grech, A., Schlaefer, J., Andutta, F. P., Lambrechts, J., Wolanski, E., and Hamann, M. (2015). Modelling the Fate of Marine Debris along a Complex Shoreline: Lessons from the Great Barrier Reef. Estuarine, Coastal and Shelf Science 167:414-426.

Dee, D. P., Uppala, S. M., Simmons, A. J., Berrisford, P., Poli, P., Kobayashi, S., Andrae, U., Balmaseda, M. A., Balsamo, G., Bauer, P., Bechtold, P., Beljaars, A. C. M., van de Berg, L., Bidlot, J., Bormann, N., Delsol, C., Dragani, R., Fuentes, M., Geer, A. J., Haimberger, L., Healy, S. B., Hersbach, H., Hólm, E. V., Isaksen, L., Kållberg, P., Köhler, M., Matricardi, M., McNally, A. P., Monge-Sanz, B. M., Morcrette, J. J., Park, B. K., Peubey, C., de Rosnay, P., Tavolato, C., Thépaut, J. N., and Vitart, F. (2011). The ERA-Interim Reanalysis: Configuration and Performance of the Data Assimilation System. Quarterly Journal of the Royal Meteorological Society 137(656):553-597.

Duhec, A. V., Jeanne, R. F., Maximenko, N., and Hafner, J. (2015). Composition and Potential Origin of Marine Debris Stranded in the Western Indian Ocean on Remote Alphonse Island, Seychelles. Marine Pollution Bulletin 96(1-2):76-86.

GESAMP (2016). Sources, Fate and Effects of Microplastics in the Marine Environment: Part Two of a Global Assessment (GESAMP No. 93). London: GESAMP.

Hall, K. (2000). Impacts of Marine Debris and Oil: Economic and Social Costs to Coastal Communities. Lerwick: Kommunenes Internasjonale Miljøorganisasjon (KIMO).

Hong, J. S., Moon, J. H., Kim, T., and Lee, J. H. (2018). Impact of Ocean-Wave Coupling on Typhoon-Induced Waves and Surge Levels around the Korean Peninsula: A Case Study of Typhoon Bolaven. Ocean Dynamics 68:1543-1557.

Hu, Z., Wang, D. P., He, X., Li, M., Wei, J., Pan, D., and Bai, Y. (2017). Episodic Surface 
Intrusions in the Yellow Sea during Relaxation of Northerly Winds. Journal of Geophysical Research: Oceans 122(8):6533-6546.

Isobe, A., Kako, S. I., Chang, P. H., and Matsuno, T. (2009). Two-Way Particle-Tracking Model for Specifying Sources of Drifting Objects: Application to the East China Sea Shelf. Journal of Atmospheric and Oceanic Technology 26(8):1672-1682.

Isobe, A., Uchida, K., Tokai, T., and Iwasaki, S. (2015). East Asian Seas: A Hot Spot of Pelagic Microplastics. Marine Pollution Bulletin 101(2):618-623.

Iwasaki, S., Isobe, A., Kako, S. I., Uchida, K., and Tokai, T. (2017). Fate of Microplastics and Mesoplastics Carried by Surface Currents and Wind Waves: A Numerical Model Approach in the Sea of Japan. Marine Pollution Bulletin 121(1-2):85-96.

Kako, S. I., Isobe, A., and Magome, S. (2010). Sequential Monitoring of Beach Litter using Webcams. Marine Pollution Bulletin 60(5):775-779.

Lebreton, L., Slat, B., Ferrari, F., Sainte-Rose, B., Aitken, J., Marthouse, R., Hajbane, S., Cunsolo, S., Schwarz, A., Levivier, A., Noble, K., Debeljak, P., Maral, H., Schoeneich- Argent, R., Brambini, R., and Reisser, J. (2018). Evidence that the Great Pacific Garbage Patch is Rapidly Accumulating Plastic. Scientific Reports $8(1): 1-15$.

Jambeck, J. R., Geyer, R., Wilcox, C., Siegler, T. R., Perryman, M., Andrady, A., Narayan, R., and Law, K. L. (2015). Plastic Waste Inputs from Land into the Ocean. Science 347(6223):768-771.

Li, G., Qiao, L., Dong, P., Ma, Y., Xu, J., Liu, S., Liu, Y., Li, J., Li, P., Ding, D., Wang, N., Olusegun A, D., and Liu, L. (2016). Hydrodynamic Condition and Suspended Sediment Diffusion in the Yellow Sea and East China Sea. Journal of Geophysical Research: Oceans 121(8):6204-6222.

Li, W. C., Tse, H. F., and Fok, L. (2016). Plastic Waste in the Marine Environment: A Review of Sources, Occurrence and Effects. Science of the Total Environment 566-567:333-349.

Maximenko, N., MacFadyen, A., and Kamachi, M. (2015). Modeling the Drift of Marine Debris Generated by the 2011 Tsunami in Japan. PICES Press 23(2):32-36.

Moy, K., Neilson, B., Chung, A., Meadows, A., Castrence, M., Ambagis, S., and Davidson, K. (2018). Mapping Coastal Marine Debris using Aerial Imagery and Spatial Analysis. Marine Pollution Bulletin 132:52-59.

Neumann, D., Callies, U., and Matthies, M. (2014). Marine Litter Ensemble Transport Simulations in the Southern North Sea. Marine Pollution Bulletin 86(1-2):219228.

North, E. W., Hood, R. R., Chao, S. Y., and Sanford, L. P. (2006). Using a Random Displacement Model to Simulate Turbulent Particle Motion in a Baroclinic Frontal Zone: A New Implementation Scheme and Model Performance Tests. Journal of Marine Systems 60(3-4):365-380.

Qian, W. and Lee, D. K. (2000). Seasonal March of Asian Summer Monsoon. International Journal of Climatology: A Journal of the Royal Meteorological 
Society 20(11):1371-1386.

Rypina, I. I., Jayne, S. R., Yoshida, S., Macdonald, A. M., and Buesseler, K. (2014). Drifter-Based Estimate of the 5 Year Dispersal of Fukushima-Derived radionuclides. Journal of Geophysical Research: Oceans 119:8177-8193.

Seo, S. and Park, Y. G. (2020). Destination of Floating Plastic Debris Released from Ten Major Rivers around the Korean Peninsula. Environment International 138: 105655 .

Seo, S. and Park, Y. G. (2021). Tracking a Coastal Wave Buoy, Lost from the Southern Coast of Jeju Island, Using Lagrangian Particle Modeling. Journal of Marine Science and Engineering 9(8):795.

Seo, S., Park, Y. G., and Kim, K. (2020). Tracking Flood Debris using Satellite-Derived Ocean Color and Particle-Tracking Modeling. Marine Pollution Bulletin 161: 111828.

Seo, S., Park, Y. G., Park, J. H., Lee, H. J., and Hirose, N. (2013). The Tsushima Warm Current from a High Resolution Ocean Prediction Model, HYCOM. Ocean and Polar Research 35(2):135-146.

Shim, W. J., Hong, S. H., and Eo, S. (2018). Marine Microplastics: Abundance, Distribution, and Composition. in Microplastic Contamination in Aquatic Environments, pp. 1-26. Amsterdam: Elsevier.

Smagorinsky, J. (1963). General Circulation Experiments with the Primitive Equations: I. The basic experiment. Monthly Weather Review 91(3):99-164.

Son, Y. B., Choi, B. J Kim, Y. H., and Park, Y. G. (2015). Tracing Floating Green Algae Blooms in the Yellow Sea and the East China Sea using GOCI Satellite Data and Lagrangian Transport Simulations. Remote Sensing of Environment 256:21-33.

van Sebille, E., Griffiesc, S. M., Abernatheyd, R., Adamse, T. P., Pavel Berlofff, P., Biastochg, A., Blankeh, B., Chassigneti, E. P., Cheng, Y., Cotter, C. J., Deleersnijder, E., Döös, K., Drake, H. F., Drijfhout, S., Gary, S. F., Heemink, A. W., Kjellsson, J., Koszalka, I. M., Lange, M., Lique, C., Macgilchrist, G. A., Marsh, R., Adame, C. G. M., Mcadam, R., Nencioli, F., Paris, C. B., Piggott, M. D., Polton, J. A., Rühs, S., Shah, S. H. A. M., Thomas, M. D., Wang, J., Wolfram, P. J., Zanna, L., and Zika J. D. (2018). Lagrangian Ocean Analysis: Fundamentals and Practices. Ocean Modelling 121:49-75.

Yoon, J. H., Kawano, S., and Igawa, S. (2010). Modeling of Marine Litter Drift and Beaching in the Japan Sea. Marine Pollution Bulletin 60(3):448-463.

Zhang, Y., Sperber, K. R., and Boyle, J. S. (1997). Climatology and Interannual Variation of the East Asian Winter Monsoon: Results from the 1979-95 NCEP/NCAR reanalysis. Monthly Weather Review 125(10):2605-2619. 